\title{
The Mobility of Robotised Work Cells IN MANUFACTURING
}

\author{
Kristo Vaher, Tavo Kangru, Tauno Otto, Jüri Riives
}
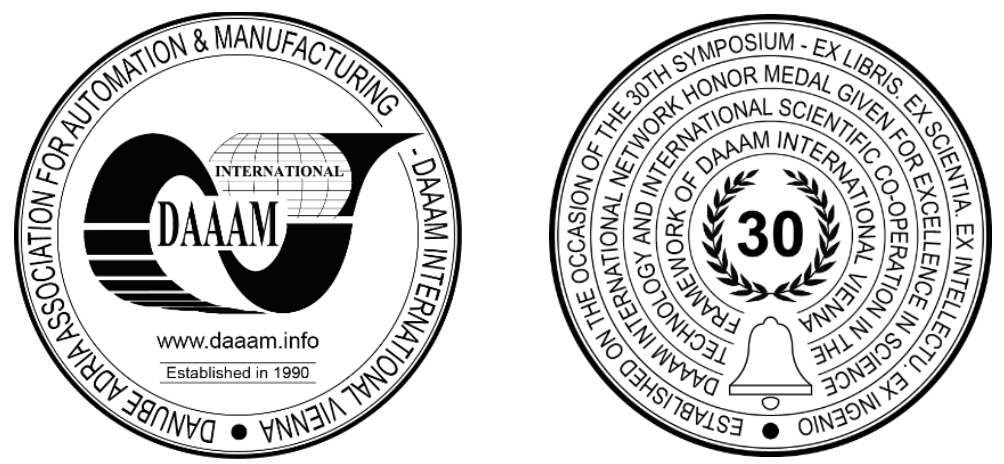

This Publication has to be referred as: Vaher, K[risto]; Kangru, T[avo]; Otto, T[auno] \& Riives, J[yri] (2019). The Mobility of Robotised Work Cells in Manufacturing, Proceedings of the 30th DAAAM International Symposium, pp.1049-1055, B. Katalinic (Ed.), Published by DAAAM International, ISBN 978-3-902734-22-8, ISSN 1726-9679, Vienna, Austria

DOI: $10.2507 / 30$ th.daaam.proceedings.146

\begin{abstract}
Many companies are already using robots, but many have not found enough applications for the robot and therefor they have not purchased it jet. One robot can be used to perform several different tasks, but it also raises the question of whether the production needs to be reorganized so that these multiple tasks are directed to the robot, or it can be solved differently where the robot moves between different tasks. In this paper different concepts will be discussed and each of its disadvantages and advantages will be highlighted. Paper also includes survey among Estonian manufacturing companies to find out which tasks are robotized and which tasks are desired to give over to robots in future. Paper also include short description about recently opened Industry 4.0 test hub where mobile robot applications are being tested and paper results will be also tested in this test hub. In general, this paper focus on solution how to use robot arm most efficient way if there is not enough job for stationary robot solution.
\end{abstract}

Keywords: Mobile robot, robot arm, manufacturing, industry 4.0

\section{Introduction}

One of the biggest problems of industry today is the shortage of qualified workforce. The development of technologies in the last decades has been extremely fast, the technologies today change much faster than generations. People from older generations often lack the knowledge and the courage to use the newest technologies. At the same time, children (and youngsters) from the younger generations lack the patience and willingness to study complicated engineering specialties. It is difficult to pinpoint the causes of this behaviour, but it is becoming clear that the industry must learn to deal with the situation and find new ways to keep the production ongoing and making profit in the future.

In order to alleviate the problem of qualified workforce, it is possible to use industrial robots and increase the automation of production. Robotization is, of course, more affordable to larger companies than to small and middle-sized enterprises (SMEs). The main precondition for using industrial robots is the production in large batches, especially in cases when there are multiple robots working simultaneously in the same system. Production monitoring system helps to identify the needed predictive maintenance and tool exchange times [1]. This, however, does not mean SMEs should not use robots at all. Collaboration robots can be successfully integrated into the work process of smaller enterprises, using interaction technologies [2]. Predictive simulations are used for fastest route planning in an industrial environment [3]. 
The development of collaboration robots and the general compliance of Industry 4.0 principles have made the implementation of industrial robots fairly easy [4], [5], [6], [7], [14].

One of the preconditions of operating an industrial robot is that it has enough working hours per day. In case of smaller enterprises that produce small batches, it would mean the reorganization of production so that the tasks performed by the robot would be directed to a stationary robot. Another option is to move manually the robot between different units of production. This may result in long pauses in working time and degrees of efficiency. The robot could, instead of waiting, fulfil another task or serve other benches. To achieve this, the production must be planned so that the benches the robot needs to serve are placed around the robot. Another option is to move the robot arm from one bench to another in the production area. It can be done by lifting it manually or by mobile robot.

In addition to the shortage of skilled labour, industries also have to deal with issues such as optimizing production times, using resources more efficiently, producing faster and smaller quantities, while ensuring high quality [13]. Robotic solutions are one of the key factor in solving these issues as well. Lack of knowledge to guide potential users of robotic sell is an essential barrier to more extensive use of robotised solutions [9].

\section{Survey among Estonian Enterprises}

In 2017, a survey was conducted among Estonian enterprises in order to map the level of robotization in production companies. Among other questions, the companies were asked about the characteristics of production in terms of batch sizes, in order to evaluate which companies could benefit from stationary and which from mobile robot cell solutions. 30 enterprises took part in the survey. The average size of the enterprises was 140 people, and according to turnover data, most of the companies could be defined as SMEs (small and middle-sized enterprises).

In addition, the survey included questions about batch/lot sizes of products and parts, and about the repeatability factor of a batch - meaning whether one part is produced multiple times or is every operation different. The survey showed that the batch sizes in $1 / 3$ of the enterprises correspond to $10-50$ units. In most cases, the repeatability of a batch was more than $50 \%$. In case of batch sizes of less than 10 units, we could see a low repeatability level (ca $10 \%$ ). With batches of more than 50 units, the repeatability level was high, more than $50 \%$. Over $60 \%$ of companies answer that more that $50 \%$ of batches are repeated constantly over the time.

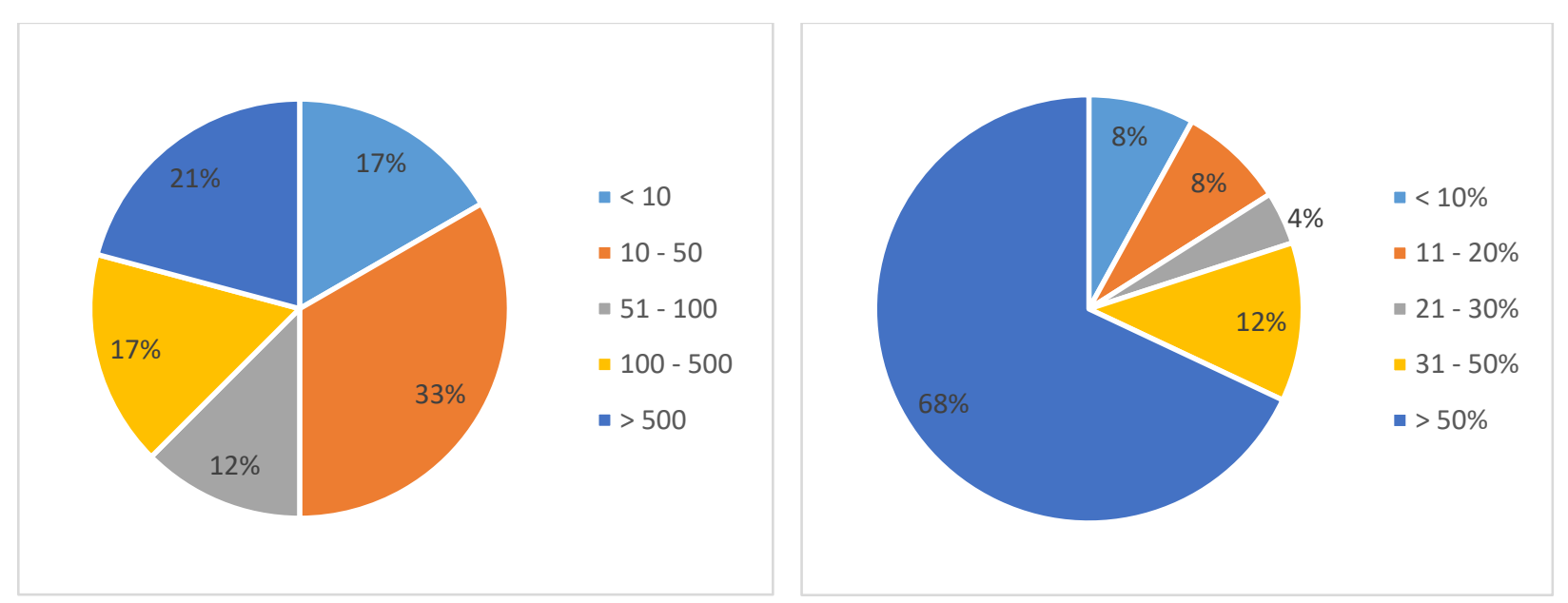

Fig. 1. Parts in lot size (left) and repeatability of the lots (right)

Based on the information from the survey, it can be concluded that most enterprises produce relatively small batches with high level of repeatability. This means that one bench is not only used for producing one product or part, and that products are being manufactured repeatedly. From the viewpoint of robotization, it means creating multiple programmes. When repeating the production cycle, a programme that has already been written can be used again.

The survey also indicates that the robots used in manufacturing are not fully occupied. Half on the enterprises use robots for up to 50-70\% of their capacity. It shows that robots could be given additional tasks, but since the companies are using mainly welding robots, it is hard to assign other jobs for them. The data shows that only $25 \%$ of enterprises use more than $70 \%$ of their robots capacity.

According to the survey, up until now, industrial robots have mainly been used in welding operations. However, the data shows that enterprises would like to use robots for other operations as well, such as mechanical processing, painting, assembling and quality control (Fig. 2). In these areas, there are various tasks that can be assigned to one robot. If it is not possible to occupy a robot fully with a certain task, it is reasonable to use the robot for many different tasks. 


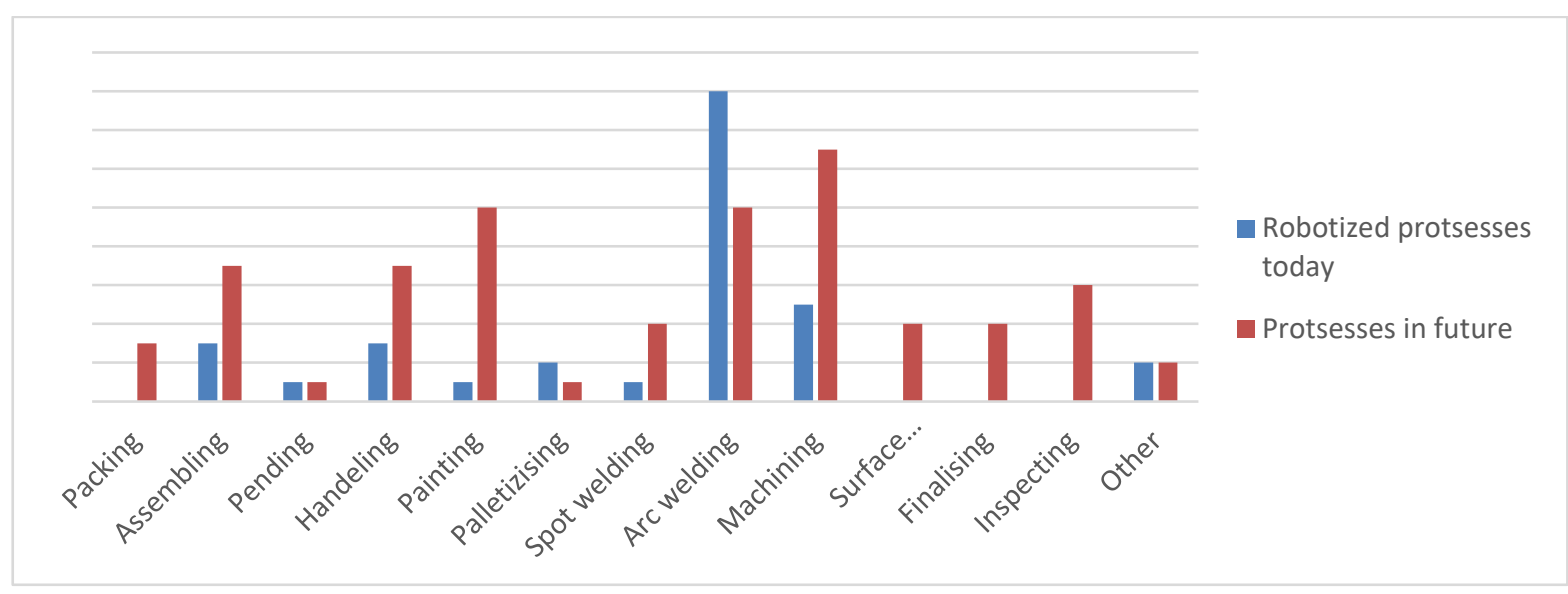

Fig. 2. Robotized protsesses today and desired processes for future

According to the Genefke scale, elaborated at Danish Technological Institute by Bo Genefke, the enterprises that took part in the survey mainly operate with tasks requiring standard and adaptable knowledge, which could be easily automated (Fig. 3). Genefke scale divides enterprises into five categories. The enterprises that belong to the first group can use standardized, easily applicable solutions. When moving to the right end of the scale, we see the complexity of tasks rising. The right end of the scale indicates enterprises who need completely new knowledge in their processes, such as enterprises and organisations dealing with research.

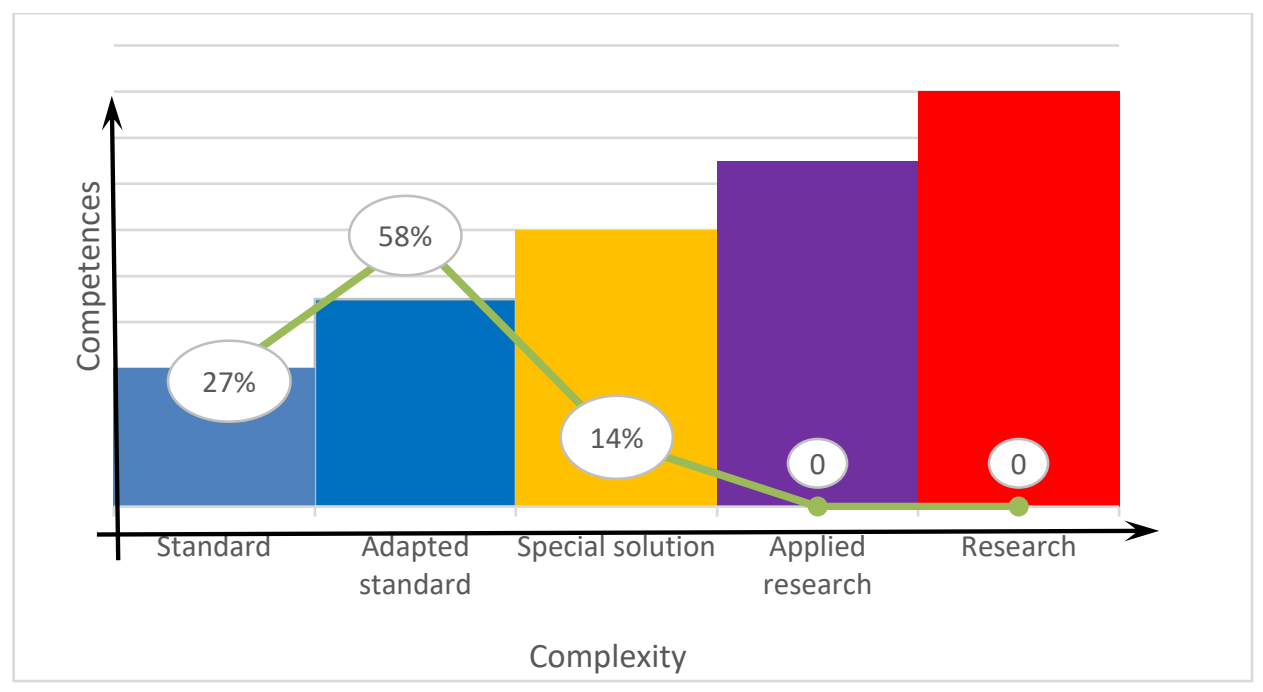

Fig. 3. Genefke scale

The survey conducted among Estonian enterprises shows that the robots used in production are mainly welding robots which are not used to their $100 \%$ capacity. At the same time, enterprises would like to use robots for other operations as well. The problem is that it is difficult to implement welding robots for other tasks, as their tool and installation is meant only for welding operations and it would be too costly to exchange those. Instead, it would be feasible to use a new robot for operations other than welding. In case the new robot cannot be fully occupied with one type of task, it would be beneficial to find a universal solution where the robot could perform different types of tasks, such as serving the CNC bench and packaging.

\section{Manufacturing testbed for Industry 4.0}

Most of the testbeds related research is related to cyber security and electrical grids, while robotics and manufacturing are in minority [10]. In current research the testbed for applying Industry 4.0 principles through robotics and manufacturing has been developed at TTK University of Applied Sciences [8]. The testbed laboratory features a functioning production system, starting from entering the order to Enterprise Resource Planning (ERP) until the pickup at the package station by an end consumer. In between, there is the whole manufacturing process together with several robots. The production system is modular and flexible. The system is easily reconfigurable when new products are added, and modules can be added or reconfigured when production volumes increase. Main purpose of this lab was to get test 
bed where different scenarios can be tested according to Industry 4.0 principles. Automatization components from Estonian manufacturers were also integrated to connect the concept regionally and also educate visitors and students.

One of the modules of this testbed manufacturing system is a mobile robot arm, the task of which is to serve all the other modules (Fig. 4). The main tasks of the robot arm include transporting the warehouse container between different modules and changing the plate in the 3D printer. In the testbed, similarly to state of the art international labs [11] robots from two different manufacturers have been used - the robot arm Universal Robots UR 10 and the mobile robot Mobile Industrial Robots MIR 100.

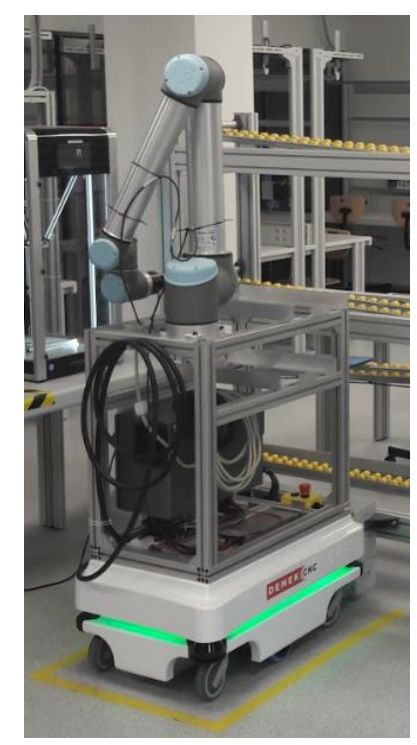

Fig. 4. Robot arm and mobile robot tandem.

Based on the mobile robotic arm module described above, practical tests will be conducted, and a prototype model developed for supporting the theoretical part of the current study. The aim is to build a base frame or a platform to the robot arm that would be separate from the mobile robot and that would be transportable by the mobile robot in the automated process together with the robot arm.

\section{Alternative solutions for increasing the performance of a robot-cell}

Today there are several different mobile robots available that are capable of moving the robot arm around in a room. For this, two different technologies must be combined. The result is a flexible solution that enables to use one robot arm in many working positions. There are solutions where a robot arm has been permanently installed into a mobile robot, such as KUKA KMR Quantec, KUKA KMR iiwa, Robotnik Kairos 3. In addition, there are many solutions of combining MIR 100 + UR10, and other robots from different manufacturers. In this case, the cost of the robot cell would be the sum of a robot arm and a mobile robot, therefore approx. doubling the cost.

However, the two work cells could be separated when, for example, more than one robot arm is used in manufacturing. In this case, one mobile robot can serve many robot arms. When combining a mobile robot and a robot arm, only one of them can work simultaneously with the other in most cases. During transport, the robotic arm is not working and when the robot arm is working, the mobile robot is standing idly. Separation of the tandem of a mobile robot and a robotic arm (fig. 5.) would considerably raise the efficiency of both units.
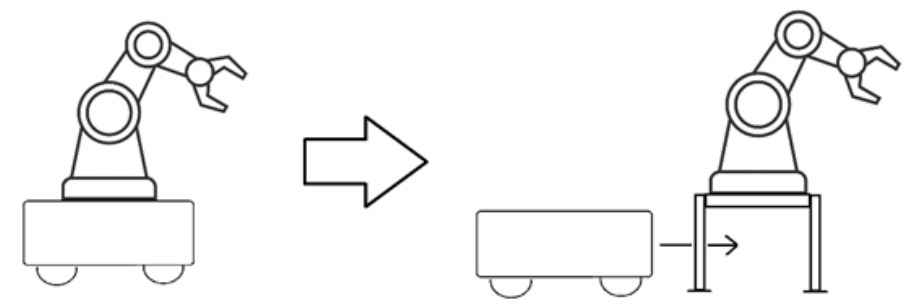

Fig. 5. Separating mobile robot from robot arm tandem

One industrial robot may easily be used for performing different working tasks. For this, a robot cell with different functionalities is needed. Many different tools can also be assembled to one robotic arm. For example, several work tools 
can be assembled to a robotic arm with a rotating multi-tool mount. Another option is to use a quick-change system (toolchange solution for immediate use). Using a rotatable multi-tool solution is a good and fast option, but its extra hardware and it add a lot of weight to the robot arm, which will therefore lower the maximum weight limit of the working task. The rotating multi-tool solution is being produced, for example, by New Scale Robotics. The advantage of a quick-change system compared to the rotatable multi-tool solution is its smaller weight. However, with this solution, less time will be left for the production process itself, as the change of the tool must be done in distance from the work object, therefore, it will take some time to detach a tool and replace it with a new one. Quick-change solutions are offered, for example, by the company Stäubli. Both solutions have their advantages and disadvantages and the choice depends largely on the implementation specialty and the characteristics of the working process.

Regardless of the type of a work tool of a robotic arm, the more important question is whether to bring the work tasks to the robot or to take the robot to the task(s). In case a robot will be brought into a working production facility, it is important to assess whether and how much will the system be reorganized and how much additional investments will be needed. The following pages focus on the three possible options of integrating robots with different working tasks.

\subsection{Solution 1}

In order to use one robot for many different operations, production should be planned so that the automated tasks are moved to the robot and the robot itself is stationary (Fig. 6.). In this case, the robot is the central object of production and everything else should be positioned accordingly. This would be a typical solution for a production facility using cage robots, where, in addition to the investment of buying a new robot, a security zone must be built around the robot. This is the option where the integration of a robot to an existing industrial environment will require a certain amount of reconfiguration. Production lines and other tasks should be moved towards the robot. In most cases, this means production would be stopped for a longer period of time.

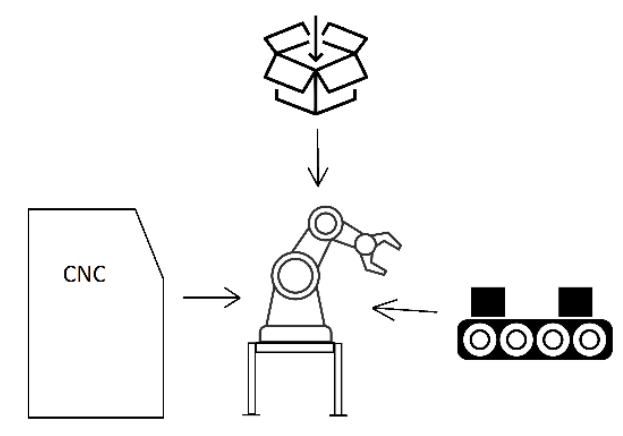

Fig. 6. Tasks directed to robot

\subsection{Solution 2}

The second option is to leave the existing production environment as it is and move the robot in between different working positions. In this case, the robot will be taken from one working position to another by a human (Fig. 7). The central object in the process is the human who has to be ready to move the robot at any time as soon as the production process requires. In this case, the manufacturing process will not change much. The moving of the robot requires the presence of a human, who will move the robot from one position to another in between working tasks. To employ an individual just for moving robots, however, may not be efficient. This solution may also cause time delays, at it may take time for a human to arrive to the robot after it has finished work. Similar solution was done by OpiFlex.

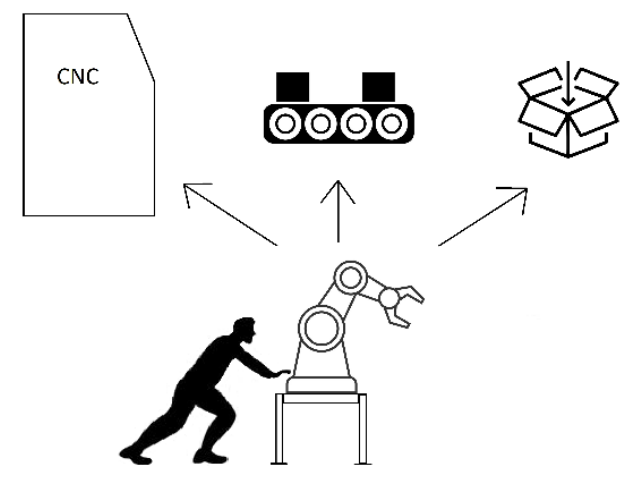

Fig. 7. Robot arm is moved between tasks by human 


\subsection{Solution 3}

The third option is to automate the moving process of the robot arm by using a mobile robot (Fig. 8). With this solution, no part of the production takes the central role, as the whole process is fully automated and works as a compact whole. The manufacturing process can be planned with high accuracy level. For example, in case of a robot serving a CNC machine, it can be quite accurately calculated when the batch will be finished. By this time, a mobile robot can be sent to fetch the robotic arm, and it can be moved to the next task. In this option, there is no need for a human who would take the robot arm from one working station to another. Connecting the robot arm to the electricity network and other communications will take place automatically through the base frame of the robotic arm.

This solution presupposes that every working position need for the robot arm an automatic docking station, which has been linked with the centralized systems such as electricity, compressed air, data, etc.

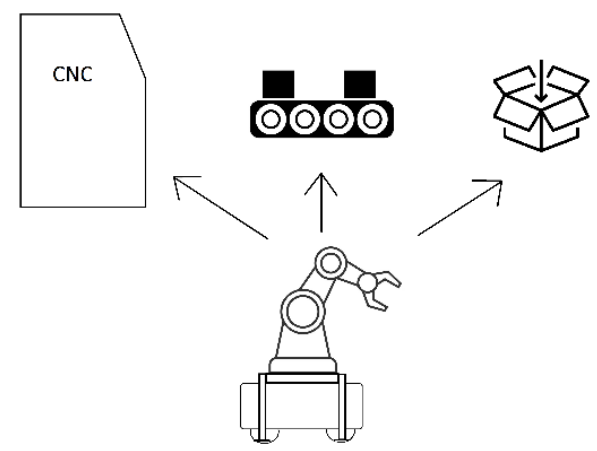

Fig. 8. Robot arm is moved between tasks by mobile robot

\subsection{Comparison of solutions}

The following charts (Table 1.) illustrate the levels of the changes that need to be done and the impact to the manufacturing process in case of different options of taking in use a robot arm solution. The chart does not bring out the factors that are similar for all the options, such as programming, implementation to the process, maintenance etc. Evaluation is done based on comparing those three solutions with each other and marks are given witch solution takes the highest credit and witch one the least.

\begin{tabular}{|l|c|c|c|c|}
\hline & $\begin{array}{c}\text { Need for } \\
\text { reconfiguring the } \\
\text { production }\end{array}$ & $\begin{array}{c}\text { Need for } \\
\text { additional } \\
\text { appliances }\end{array}$ & $\begin{array}{c}\text { Need for } \\
\text { additional } \\
\text { software }\end{array}$ & $\begin{array}{c}\text { Need for } \\
\text { additional } \\
\text { human work } \\
\text { hours }\end{array}$ \\
\hline Solution 1 & High & Low & Low & Low \\
\hline Solution 2 & Low & Low & Low & Medium \\
\hline Solution 3 & Low & $\begin{array}{c}\text { High (mobile } \\
\text { robot, dock's) }\end{array}$ & High $\left(\mathrm{MES}^{1}\right)$ & Low \\
\hline
\end{tabular}

Table 1. Integration needs for a robot solution implementation

The chart below (Table 2) compares the benefits of integrating a robot arm solution in factory. Case by case it can be different but in general it shows the different between those three solution results.

\begin{tabular}{|l|c|c|c|c|}
\hline & $\begin{array}{c}\text { Level of } \\
\text { automation }\end{array}$ & $\begin{array}{c}\text { Rise of Efficiency } \\
\text { level }\end{array}$ & $\begin{array}{c}\text { 24/7 (full time) } \\
\text { working capacity }\end{array}$ & Flexibility \\
\hline Solution 1 & High & High & High & Low \\
\hline Solution 2 & Medium & Medium & Medium & High \\
\hline Solution 3 & High & Rather high & High & High \\
\hline
\end{tabular}

Table 2. Benefits of integrating a robot arm to a production facility

\footnotetext{
${ }^{1}$ MES - Manufacturing execution systems
} 
Different solutions require very different investments. Investing in automation is inevitable. New equipment and software must be introduced and money spent on programming. As a result, the goal is to achieve more efficient production. Efficiency gains are expressed differently by each company. It can be one of the factors in the table, or it can be all of the actions taken together. In solution three the score is high for all the factors. In future developments the testbed can be implemented for investigation of Industry 4.0 Digital maturity Model 4.0 [12].

\section{Conclusion}

Survey among Estonian companies brought out that implementation of industrial robots by SMEs has been slow. One reason for that is that, there is not enough work assignments for stationary robots without reorganize production in a big scale. At same time, the companies are interested to give more jobs to the robots. As a result of this work, a solution has been proposed in which the robot arm is moved between different working positions and the transport part is filled by another robot - a mobile robot. Such a solution can give high level of work hours to the robotic arm without the need to reorganize existing factory in big scale. When using a mobile robot, there is no need for a separate person who should take care to move the robot arm between different workstations. Carrying a robotic arm on a mobile robot gives you the opportunity to apply a robotic arm around the clock and it gives you flexibility to reconfigure your production more easily rather the solution where robot arm is stationary.

The aim of the thesis is to develop a technical solution for the mobile use of a robot arm, accompanied by a prototype and an assessment of its applicability. Further on, a design model will be developed for configuring a mobile robot to the robot arm. MIR 100 will be used as a mobile robot and UR 10 as a robot arm. A functional model and a cost-analysis will be developed. After this, a practical model will be built, and necessary tests completed for assessing the model's applicability.

\section{References}

[1] Eiskop, T.; Snatkin, A.; Karjust, K.; Tungel, E. (2018). Production monitoring system design and implementation. Proceedings of the Estonian Academy of Sciences, 67 (1), 10-16.10.3176/proc.2017.4.02/

[2] Berg, J.; (2019). Human-Robot-Interaction for mobile industrial robot teams. Procedia CIRP. 79. 10.1016/j.procir.2019.02.080.

[3] Grijalva, G.; Chavez D.; Camacho, O. (2018). Material Distribution with Mobile Robots in an Industrial Environment: System design and simulation. IFAC-PapersOnLine. 51. 650-655. 10.1016/j.ifacol.2018.07.354.

[4] Lu, Y. (2017). Industry 4.0: a Survey on Technologies, Applications and Open Research Issues, Journal of Industrial Information Integration. 6. 10.1016/j.jii.2017.04.005

[5] Robla-Gomez, S.; Becerra, V.M.; Llata, J.R, et al. (2017). Working Together: A Review on Safe Human-Robot Collaboration in Industrial Environments. IEEE Access. PP. 1-1. 10.1109/ACCESS.2017.2773127.

[6] Loun, K.; Riives, J. ; Otto, T. (2012). Workplace performance and capability optimization in the integrated manufacturing. Proceedings of 8th International Conference of DAAAM Baltic Industrial Engineering, 2: 8th International DAAAM Baltic Conference In Estonia. INDUSTRIAL ENGINEERING, 19 - 21st April 2012, Tallinn. Ed. Otto, T. Tallinn.

[7] Kuts, V.; Otto, T.; Tähemaa, T.; Bondarenko, Y. (2019). Digital twin based synchronised control and simulation of the industrial robotic cell using virtual reality. Journal of Machine Engineering, 19 (1), $128-145.2010 .5604 / 01.3001 .0013 .0464$.

[8] Vaher, K.; Vainola, V.; Otto, T. (2019). Industry 4.0 Laboratory. Industry 4.0, Technological Basis of "Industy 4.0", 1/5: IV International Scientific Conference, Industry 4.0. Summer session, 24-27.06.2019, Burgas, Bulgaria. Industry 4.0 Proceedings: 108 Rakovski str; 1000 Sofia.

[9] Iglesias, I.; Sebastián, M.A.; Ares. J.E. (2015). Overview of the State of Robotic Machining: Current Situation and Future Potential. Procedia Engineering. 132. 911-917. 10.1016/j.proeng.2015.12.577.

[10] Salunkhe, O.; Gopalakrishnan, M.; Skoogh, A. et al. (2018). Cyber-Physical Production Testbed: Literature Review and Concept Development, Procedia Manufacturing, 25: 2-9, http://dx.doi.org/10.1016/j.promfg.2018.06.050

[11] Papa, M.; Kaselautzke, D.; Stuja, K. \& Wolfel, W. (2018). Different Safety Certifiable Concepts for Mobile Robots in Industrial Environments Proceedings of the 29th International DAAAM Symposium "Intelligent Manufacturing \& Automation", 24-27th October 2018, Zadar, Croatia, Volume 29, No.1, ISSN 1726-9679, ISBN 978-3-90273420-4. Ed. B. Katalinic / Published by DAAAM International, Vienna, Austria, EU, 2018

[12] Gajsek, B.; Marolt, J.; Rupnik, B.; Lerher, T. \& Sternad, M. (2019). Using Maturity Model and Discrete-Event Simulation for Industry 4.0 Implementation International Journal of Simulation Modelling Volume 18: Number 3: September 2019.

[13] Reinhart G. (2017). Handbuch Industrie 4.0: Geschäftsmodelle, Prozesse, Technik. München: Hanser.

[14] Sell, R; Otto, T. (2008). Remotely controlled multi robot environment. Proceedings of 19th EAEEIE Annual Conference: 19th EAEEIE Annual Conference, Tallinn, Estonia, June 29 - July 2, 2008. Tallinn, 20-25.10.1109/EAEEIE.2008.4610152. 